\title{
Caixas de histórias como estratégia auxiliar do enfrentamento da hospitalização de crianças e adolescentes com câncer ${ }^{1}$
}

\author{
Nathália Rodrigues Garcia-Schinzaria, Luzia Iara Pfeifer ${ }^{\mathrm{a}}$, Amanda Mota Pacciulio Sposito ${ }^{\mathrm{b}}$, \\ Jair Lício Ferreira Santos ${ }^{\mathrm{a}}$, Lucila Castanheira Nascimento ${ }^{\mathrm{c}}$, Maria Paula Panúncio-Pinto ${ }^{\mathrm{a}}$ \\ ${ }^{a}$ Faculdade de Medicina de Ribeirão Preto, Universidade de São Paulo - USP, Ribeirão Preto, SP, Brasil \\ ${ }^{\text {b} E n f e r m a r i a ~ d e ~ O n c o-h e m a t o l o g i a ~ P e d i a ́ t r i c a, ~ H o s p i t a l ~ d a s ~ C l i ́ n i c a s ~-~ H C, ~ R i b e i r a ̃ o ~ P r e t o, ~ S P, ~ B r a s i l ~}$ \\ ${ }^{\mathrm{c}}$ Escola de Enfermagem de Ribeirão Preto, Universidade de São Paulo - USP, Ribeirão Preto, SP, Brasil
}

\begin{abstract}
Resumo: Introdução: A contação de histórias em ambiente hospitalar contribui para a diminuição de tensões e ansiedades, configurando-se como uma possibilidade de estratégia de enfrentamento da hospitalização para tratamento oncológico. Objetivo: Identificar e analisar as contribuições do Caixa de Histórias (programa de contação de histórias) para o enfrentamento da hospitalização infanto-juvenil. Procedimentos metodológicos: Pesquisa aplicada, não experimental, transversal, descritiva e de caráter qualiquantitativo desenvolvida em uma enfermaria de oncopediatria do interior paulista. Participaram do estudo 20 crianças e adolescentes de 4 a 15 anos. A coleta de dados envolveu as etapas: (1) pré-teste (apontar na escala ou expressar verbalmente qual das faces representava seus sentimentos naquele momento), (2) registro do comportamento das crianças durante as contações das histórias e (3) pós-teste (apontar na escala ou expressar verbalmente qual das faces representava o que estava sentindo após a contação da história). Resultados: Os participantes interagiram com as pessoas presentes durante as contações das histórias (interação com as duplas de graduandas de Terapia Ocupacional e interação com seus pares) e com os materiais das caixas (manipulação dos objetos da caixa e participação na realização da atividade proposta), demonstraram habilidades cognitivas (atenção e imaginação) e motivação (animação e curiosidade despertada pela história). Nove participantes modificaram significativamente seu estado emocional após as contações de histórias, com $p$ valor igual a 0,0111. Conclusões: O Caixa de Histórias mostrou-se uma importante intervenção no auxílio do enfrentamento do câncer infanto-juvenil, resgatando o universo lúdico e facilitando a recuperação de um estado saudável.
\end{abstract}

Palavras-chave: Humanização da Assistência, Hospitalização, Oncologia, Saúde da Criança, Saúde do Adolescente.

\section{The use of story boxes as an adjuvant strategy to cope with hospitalization of children and adolescents with cancer}

\begin{abstract}
Introduction: Storytelling in hospital environments contributes to the reduction of tension and anxiety; it is, therefore, a possible strategy to cope with hospitalization of patients under cancer treatment. Objective: To identify and analyze the contributions of the program "Box of Stories" (storytelling program) in coping with hospitalization of children and adolescents. Methodological Procedures: It is a non-experimental, cross-sectional, descriptive, applied research of quali-quantitative approach conducted in a pediatric oncology unit in the countryside of Sao Paulo state. Twenty children and adolescents ages 4 to 15 participated in the study. Data collection consisted of (1) pretest (indication on the scale of faces or verbal expression of one's feeling at that moment); (2) record of the behaviors of children during the storytelling; and (3) posttest (indication on the scale of faces or verbal expression of
\end{abstract}

Autor para correspondência: Luzia Iara Pfeifer, Departamento de Neurociências e Ciências do Comportamento (Secretaria), Faculdade de Medicina de Ribeirão Preto, Universidade de São Paulo, Av. Bandeirantes, 3900, $4^{\circ}$ andar, Monte Alegre, CEP 14048-900, Ribeirão Preto, SP, Brasil, e-mail: luziara@fmrp.usp.br

Recebido em 17/10/2013; Revisão em 8/4/2014; Aceito em 14/5/2014. 
one's feeling after the storytelling). Results: The participants interacted with the people present during storytelling (interaction with undergraduate students of occupational therapy and with peers) as well as with material from the boxes (manipulation of objects and participation in the activity proposed), and demonstrated cognitive abilities (attention and imagination) and motivation (liveliness and curiosity about the stories). Nine participants presented significant changes in their emotional state after the storytelling $(p=0.0111)$. Conclusions: The use of story boxes proved to be an important intervention in improving the way children and adolescents with cancer cope with hospitalization, restoring their playful universe and facilitating health recovery.

Keywords: Humanization of Assistance, Hospitalization, Medical Oncology, Child Health, Adolescent Health.

\section{Introdução}

Apesar de ser uma patologia rara na infância, o câncer é a segunda causa mais frequente de óbito entre crianças e adolescentes nos países desenvolvidos (KAATSCH, 2010). No Brasil, o Instituto Nacional de Câncer (INCA) estima que de 2012 a 2013 surjam 11.530 novos casos de câncer em crianças e adolescentes no país, excetuando-se os tumores de pele não melanoma (BRASIL, 2011).

Estima-se que em torno de $70 \%$ das crianças acometidas de câncer, se diagnosticadas precocemente e tratadas adequadamente em centros especializados, podem ser curadas (SILVA; GALLEGO; TEIXEIRA, 2006). Entretanto, muitas vezes a cura ocorre ocasionando desgastes e alteraçôes físicas, sociais, econômicas e emocionais do paciente e de seus familiares (ROLLINS, 2005) e o diagnóstico, ainda socialmente estigmatizado, gera medo, culpas, incertezas e vulnerabilidade, tanto na criança quanto em sua família (MACIEIRA; BARBOZA, 2009).

$O$ câncer provoca diversas transformações no cotidiano da criança ou adolescente, devido às internaçôes frequentes e convivência com pessoas estranhas, além dos procedimentos invasivos e dolorosos aos quais são submetidos (ALDISS et al., 2008; MENEZES et al., 2007). A doença e o tratamento têm impacto sobre o bem-estar físico e mental da criança e do adolescente (BRAAM et al., 2010). A hospitalização amedronta as crianças, o que pode afetar seu estado emocional e sua relaçáo familiar, prejudicando, consequentemente, o tratamento (PARCIANELLO; FELIN, 2008).

A hospitalização pode causar ainda alteraçôes e atrasos no desenvolvimento da criança e adolescente com câncer devido à ruptura do cotidiano, imposiçáo de uma nova rotina, afastamento da escola, separação dos pais, amigos e familiares, privação do brincar e lazer (PEDROSA et al., 2007; PFEIFER; MITRE, 2008; MOTTA; ENUMO, 2010) e limitação de estímulos adequados e saudáveis. Percebe-se, portanto, a necessidade de mobilização de recursos internos (comportamento, cogniçâo e estados afetivos) e externos à criança ou adolescente (recursos do ambiente físico e social), para que eles possam enfrentar essa nova situação (MOTTA; ENUMO, 2010). Considera-se enfrentamento, aqui, um processo emocional, comportamental e cognitivo visando a adaptação a situaçóes que mudam em cada etapa da doença (PEÇANHA, 2008).

Motta e Enumo (2010), após extensa revisão de literatura, alertam para a necessidade do desenvolvimento de estratégias de intervenção que contribuam para o enfrentamento da hospitalização e referem que a característica lúdica deve estar presente nessas intervençóes, sendo que o brinquedo, ou o componente lúdico, tem então sua função de diversão estendida à possibilidade de elaboração de sentimentos e aprendizagem de novos comportamentos (funçôes educativas e terapêuticas). Um dos benefícios imediatos da brincadeira é a produção de estratégias e comportamentos inovadores, gerados a partir do senso de domínio e autoeficácia que ela possibilita, permitindo à criança desenvolver respostas alternativas a ambientes novos e desafiantes, como o hospital (REIS; BICHARA, 2010).

A constatação de que crianças e adolescentes continuam se desenvolvendo durante a hospitalização, somada à noção de humanização da assistência hospitalar e integralidade do cuidado, têm gerado a necessidade de se considerar a criança ou adolescente internados como indivíduos com demandas não apenas de ordem médica mas também sociais e emocionais (REIS; BICHARA, 2010). A contação de histórias em ambiente hospitalar contribui para a diminuição de tensōes e ansiedades, podendo aliviar a dor, levar alegria e confiança para muitas crianças internadas (MORENO et al., 2003), configurando, portanto, possibilidade de estratégia que auxilia as crianças e adolescentes no enfrentamento da hospitalização para tratamento oncológico. As histórias auxiliam na superação do medo, da tristeza, diminuindo o foco na doença e proporcionando um alívio e melhor aceitação do tratamento através da entrada no universo da fantasia (BERNARDINO; ELLIOTT; ROLIM NETO, 2012). 
Uma metodologia utilizada para contar histórias para crianças e adolescentes hospitalizados e permitir que eles participem ativamente do processo é o programa Caixa de Histórias, o qual vem sendo desenvolvido, de forma sistemática, desde 2005 nas enfermarias de pediatria de um hospital universitário no interior de Sáo Paulo. Graduandos de Terapia Ocupacional, após um processo de capacitação inicial de 33 horas de aulas teóricas e oficinas e de supervisão semanal com os coordenadores do programa, para troca de informaçôes e discussão das vivências, passam a realizar, em duplas, a atividade de contação de histórias junto às crianças e adolescentes internados. Esse programa utiliza como recursos bonecos e outros elementos lúdicos, os quais se encontram dentro de uma caixa, que, muitas vezes, também integra o cenário (PANÚNCIO-PINTO; PFEIFER, 2010).

O Caixa de Histórias é composto por três etapas básicas: inicialmente a história infantil é contada por uma dupla de graduandos de Terapia Ocupacional, utilizando os recursos da caixa confeccionada especialmente para esse fim; em seguida, as crianças/ adolescentes são convidadas a explorar os materiais da caixa, recontando a história de acordo com seu interesse e compreensão, individualmente ou em grupo; e, finalmente, uma atividade lúdica relacionada à temática da história é proposta para as crianças/ adolescentes, como pintura, confecção de objetos e colagem (GARCIA et al., 2012).

Vale ressaltar que, devido às diferenças presentes nas diferentes faixas etárias, as histórias são adaptadas conforme a etapa do desenvolvimento no qual a criança ou adolescente se encontra. Portanto, no caso dos adolescentes, as histórias contadas são condizentes com seus gostos e desejos, assim como as atividades realizadas são compatíveis com cada faixa etária.

Partindo-se do pressuposto de que a participação de crianças e adolescentes em todas as etapas que compóem o programa Caixa de Histórias possibilita a eles o desenvolvimento de estratégias para auxiliá-los no enfrentamento da hospitalização, o presente estudo tem como objetivo identificar e analisar as contribuiçóes do Caixa de Histórias no enfrentamento da hospitalização infanto-juvenil.

\section{Metodologia}

Esta é uma pesquisa aplicada, não experimental, transversal, descritiva, de caráter qualiquantitativo, desenvolvida em uma enfermaria de oncopediatria de um hospital universitário do interior de São
Paulo. Todos os aspectos éticos de pesquisas com seres humanos foram observados e o estudo foi aprovado pelo Comitê de Ética em Pesquisa do referido hospital (processo HCRP n. 15.669/2005).

Uma das pesquisadoras acompanhou as duplas de graduandos de Terapia Ocupacional que participavam do Caixa de Histórias e, sempre antes de ser iniciada a intervenção com a metodologia do programa, essa pesquisadora convidava as crianças e adolescentes internados a participarem do estudo. Nos casos de aceitação, foi solicitada a autorização de seu acompanhante por meio da assinatura do Termo de Consentimento Livre e Esclarecido.

Participaram do estudo 12 crianças e oito adolescentes de 4 a 15 anos, totalizando 20 participantes (14 meninas e seis meninos), internados na enfermaria do referido hospital entre outubro de 2008 e julho de 2009, nos dias estipulados para a realização do Caixa de Histórias (uma vez por semana). A coleta de dados ocorreu na própria enfermaria, sendo que a aplicação de todas as etapas de coleta demandou um tempo médio de 40 a 50 minutos por participante.

Baseados nas quatro faces da Escala AUQEI, Autoquestionnaire Qualité de Vie Enfant Imagé (ASSUMPÇÃO JÚNIOR et al., 2000), os pesquisadores propuseram uma nova versão contendo a representação de ambos os gêneros (masculino e feminino), exprimindo as emoçôes: Muito alegre, Alegre, Triste e Muito triste; as faces foram desenhadas por Marcelo Matsuhiro Okama, por meio da técnica do Mangá, que tem por característica traços intensos e fortes, que enaltecem as expressóes. Essa versão adaptada, apresentada na Figura 1, já foi utilizada na pesquisa de Pfeifer et al. (2013) e se mostrou eficaz para atingir os objetivos propostos.

Antes da intervenção por meio das Caixas de Histórias, um dos pesquisadores mostrava as faces da escala adaptada para as crianças e adolescentes, ao mesmo tempo em que fornecia uma explicação verbal, compatível com a faixa etária do participante, acerca do sentimento vinculado a cada expressão (muito alegre, alegre, triste e muito triste). Em seguida, solicitava que a criança ou adolescente relatasse algum motivo ou situação que o tenha levado a sentir cada uma das emoções demonstradas. Tal procedimento verifica se o participante compreende a diferença entre cada um dos quatro estados emocionais presentes na escala utilizada; discernir uma emoção da outra e ser capaz de realizar associaçôes condizentes em um parâmetro comum entre a emoçáo e a representação do sentimento na ilustração foi um dos critérios de inclusão no estudo. Realizada adequadamente a associação entre imagens e sentimentos proposta pelo 

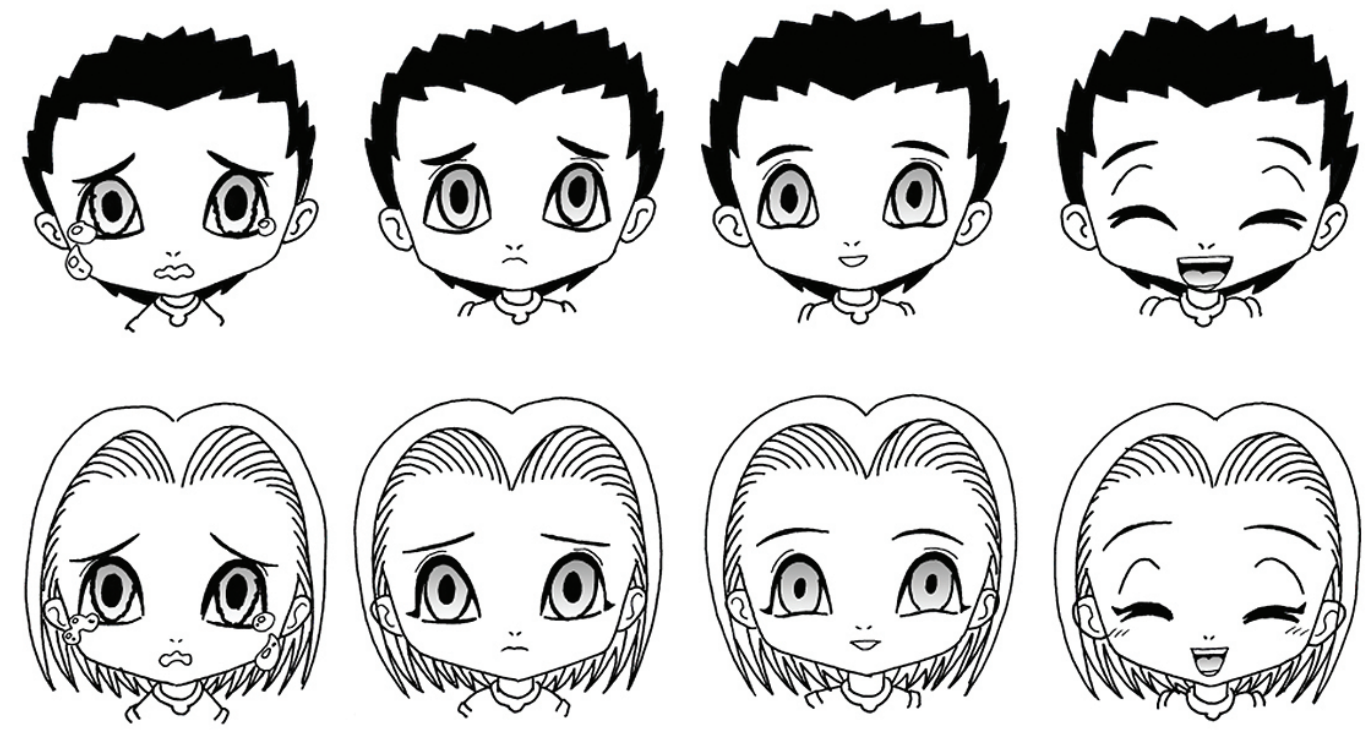

Muito triste

Triste

Alegre

Muito Alegre

Figura 1. Faces expressando as emoções - gêneros masculino e feminino.

instrumento foi realizado o pré-teste, solicitando-se que cada participante apontasse na escala ou expressasse verbalmente qual das faces representava o que estava sentindo naquele momento.

Após a aplicação da escala (pré-teste) foi realizada a intervenção Caixa de Histórias (contação da história; exploração dos materiais contidos na caixa; recontação da história com as próprias palavras da criança ou adolescente; e atividade lúdica) pelas duplas de graduandos e, durante ela, uma das pesquisadoras deste estudo realizava o registro, em um diário de campo, dos comportamentos, postura e comunicação não verbal das crianças e adolescentes (expressóes faciais e/ou corporais).

Quinze minutos após a intervenção Caixa de Histórias foram novamente apresentadas as faces que expressavam as emoçóes e foi perguntado a cada participante qual era a que mais representava o seu sentimento naquele instante (pós-teste).

Foi realizada a análise de conteúdo dos registros do diário de campo, do tipo temática indutiva, a qual consiste em uma forma de análise dirigida pelos dados/registros, uma vez que interesses teóricos do pesquisador náo conduzem a identificaçáo dos temas (BRAUN; CLARKE, 2006). Na análise indutiva, os conceitos, significados e categorias proveem dos dados coletados (POLIT; BECK, 2004), construindo a partir deles as categorias e, então, a teoria. A análise dos dados seguiu os passos a seguir: familiarização com os dados, construção de códigos iniciais, pesquisa por temas, revisão dos temas encontrados, definiçẫo e nomeação dos temas e elaboração do relatório final.

Os dados relativos aos sentimentos referidos pelas crianças/adolescentes antes e após a contação da história foram analisados através das categorias Muito alegre, Alegre, Triste e Muito triste, sendo realizada, posteriormente, análise comparativa dos resultados de antes e depois da intervenção Caixa de Histórias através do teste estatístico de Wilcoxon (SIEGAL; CASTELLAN JUNIOR, 2006).

\section{Resultados}

\subsection{Descrição dos comportamentos das crianças e adolescentes e dos acompanhantes durante a prática}

De acordo com a análise dos registros dos comportamentos das crianças e adolescentes foram identificadas quatro categorias de análise e oito subcategorias (entre parênteses): interação com pessoas (interação com as duplas de graduandas de Terapia Ocupacional e interação com seus pares); interação com materiais (manipulação dos objetos da caixa e participação na realização da atividade proposta); habilidades cognitivas (atenção na história e imaginação); e motivação (animação e curiosidade despertada pela história).

Quanto à interação com pessoas, foi verificado quando as crianças/adolescentes questionavam e 
respondiam as perguntas das duplas de graduandas e dos familiares, interagiam com outras crianças/ adolescentes, mostravam as atividades realizadas para membros da equipe ou outras pessoas e falavam sobre seu cotidiano. A interação com as duplas de graduandas ocorreu para $90 \%$ das crianças/ adolescentes e a interação com outras crianças/ adolescentes, para apenas 30\% dos participantes.

A interação com materiais foi observada quando as crianças/adolescentes utilizavam os objetos da caixa para mostrar para outras pessoas, para recontar a história com suas palavras ou, ainda, para inventar outra história, além de ajudarem as duplas de graduandas, ao término da intervenção, a guardarem os materiais na caixa, sendo que $80 \%$ das crianças/ adolescentes manipularam os objetos da caixa (logo em seguida à contação da história pela dupla de graduandos). Foi observado que $90 \%$ das crianças/ adolescentes envolveram-se na atividade lúdica proposta após a etapa de exploração dos materiais da caixa, realizando atividades como pintura, confecção de objetos e colagem.

Quanto às habilidades cognitivas, 100\% das crianças/adolescentes mantiveram atenção na história, fato observado por meio do olhar atento na encenação e através das mudanças na expressão facial, coerentes com o desenrolar da história, além disso, notou-se que elas conseguiram, posteriormente, recontar a história adequadamente. Em relação à imaginação, ela foi observada em $30 \%$ das crianças durante a exploração dos materiais e contação da história, por meio da utilização do faz de conta durante a representaçáo das cenas e manipulaçáo dos elementos da caixa (extrapolando a história para atividades do cotidiano deles, como tomar banho, escovar os dentes, alimentar-se) e/ou acrescentando novos personagens e cenários.

Quanto à motivação, $80 \%$ das crianças/ adolescentes apresentaram-se animados e $60 \%$ demonstraram curiosidade. A animação foi evidenciada por meio de sorrisos e da empolgaçáo ao recontar a história, na manipulação dos materiais e a interação com as pessoas presentes. A curiosidade ocorreu através de questionamentos dos participantes a respeito do modo de confecção da caixa e dos personagens, maneiras de realizar as atividades propostas, inclusive com outros tipos de materiais.

\subsection{Sentimentos antes e após a contação da história}

Quanto aos sentimentos das crianças e adolescentes antes e após a contação da história, foram atribuídos escores aos sentimentos manifestados por eles, os quais variaram entre 1 (Muito triste), 2 (Triste), 3 (Alegre) e 4 (Muito alegre).

Das 20 crianças/adolescentes participantes do estudo, nove (45\%) mudaram para uma emoção mais feliz, 10 (50\%) participantes mantiveram-se na mesma categoria de emoçáo, sendo que todos esses já se encontravam em um estado emocional positivo (alegre ou muito alegre) e apenas um mudou para uma emoção mais triste $(5 \%)$ após o Caixa de Histórias. O participante que permaneceu em um estado emocional triste não interagiu com outras pessoas e nem se mostrou motivado durante a prática realizada. Já o participante que diminuiu seu escore, apesar de interagir com outras pessoas e mostrar-se motivado, mudou seu estado emocional de muito alegre para alegre (de 4 para 3). Dentre os participantes que melhoraram de escore, $55 \%$ interagiram com as duplas de graduandas e/ou com outras crianças e adolescentes e mostraram-se motivados (demonstrando animação e curiosidade).

Analisando os resultados antes e após a contação das histórias, foi possível verificar que as crianças e adolescentes modificaram significativamente seu estado emocional, com $p$ valor igual a 0,0111 , como pode ser observado na Tabela 1:

Os resultados demonstram que os escores são maiores após a intervenção com a Caixa de Histórias. $\mathrm{O}$ teste exato realizado pela distribuição binomial aponta para um $p$ valor 0,0107 , isto é, a mediana dos escores pré-intervençáo são significativamente menores que a dos escores pós-intervenção.

\section{Discussão}

A formação do vínculo durante o brincar é importante para a recuperação da criança (MELO, 2003). Durante o desenvolvimento deste estudo verificou-se que a intervenção Caixa de Histórias possibilitou uma interação positiva entre as duplas de graduandas e as crianças e adolescentes através do diálogo sobre as histórias contadas e sobre a confecção da caixa, durante a exploração dos materiais e execução das atividades, favorecendo, assim, a socialização. Motta e Enumo (2002) realizaram um

Tabela 1. Sentimentos antes e após a intervenção com a Caixa de Histórias.

\begin{tabular}{lcc}
\hline \multicolumn{1}{c}{ Sentimentos } & Antes & Após \\
\hline Muito alegre & 8 & 13 \\
Alegre & 7 & 4 \\
Triste & 3 & 3 \\
Muito triste & 2 & 0 \\
\hline
\end{tabular}


estudo com o objetivo de avaliar as estratégias de enfrentamento da hospitalização de crianças com câncer, concluindo que as respostas das crianças indicaram a utilizaçáo predominante de estratégias como brincar, assistir TV, cantar e dançar, rezar, estudar, conversar, ouvir música, ler gibi, tomar remédio e buscar informaçôes, assim, observa-se que a Caixa de Histórias pode ser reconhecida como uma estratégia de enfrentamento da hospitalização.

Durante a manipulação dos objetos da caixa pelas crianças e adolescentes e durante a sua participação na realização das atividades propostas, notou-se a grande importância do brincar e da utilização da arte (pintura, confecção de objetos, colagem, criaçáo de outras histórias) para que eles se expressassem livremente. Assim, os resultados do comportamento dos participantes durante a intervenção vão ao encontro das ideias de Bahia (2002), que afirma que a utilizaçáo da arte como recurso terapêutico auxilia no desenvolvimento da livre expressão e possibilita o entendimento e a interpretação de experiências de crianças e adolescentes com câncer, melhorando sua qualidade de vida.

Percebeu-se que grande parte dos participantes manipulou os objetos da caixa e, de acordo com Melo (2003), o brinquedo é importante para o desenvolvimento global da criança, já que satisfaz suas necessidades básicas, auxilia na experimentação, na socialização de formas de comportamento, além de ajudar na recuperação física e psicológica da criança doente. Além disso, o brinquedo auxilia a criança hospitalizada no entendimento do que está acontecendo, amenizando temores, tensôes e a ansiedade (LEITE; SHIMO, 2008).

A apatia foi pouco evidenciada nas crianças e adolescentes da pesquisa. Mesmo com o adoecimento e a hospitalização, notou-se que eles prestaram atenção na história e interagiram com as duplas de graduandas. A maioria participou da realização das atividades propostas, evidenciando o quanto a utilização desse tipo de recurso terapêutico pode ser benéfica para crianças e adolescentes hospitalizados. No estudo de Pfeifer et al. (2013) sobre o estado emocional de crianças em situação de hospitalização, o qual utiliza o mesmo instrumento do presente estudo, foi verificado que $91,5 \%$ delas encontravam-se em estado emocional positivo (alegre ou muito alegre), sendo que a justificativa para tal sentimento relacionava-se principalmente à possibilidade de brincar no hospital e à presteza para sair do hospital.

A maioria dos participantes demonstrou curiosidade, perguntou sobre a confecçáo da Caixa de Histórias, sobre a história em si e sobre as atividades realizadas. Além disso, a imaginação, embora pouco presente no momento da intervenção, foi importante para que eles expressassem seus desejos e angústias. Quando a criança utiliza a imaginação de forma prazerosa, passa a ocorrer a repetição da situação que trouxe felicidade. Dessa forma, o brincar, quando ocorre de forma livre, possibilita a imaginação da criança, por meio de um mundo de faz de conta consciente, no entanto capaz de simular as relaçóes presentes no cotidiano dela, que vivencia simbolicamente diferentes papéis, exercitando sua capacidade de generalização e abstração (MELO, 2003).

A inclusão de intervenções terapêuticas diferenciadas, considerando o sujeito em sua totalidade psíquica e adequadas à rotina hospitalar, com o objetivo de humanizar a assistência à saúde, é importante (VASCONCELLOS; GIGLIO, 2007). Neste estudo, assim como no de Soares, Guimarães e Ribeiro (2003), percebeu-se que é essencial que as instituiçóes de saúde forneçam recursos humanos e materiais para que crianças e adolescentes adoecidos tenham suporte nas atividades lúdicas, humanizando a assistência e contribuindo, assim, para o enfrentamento positivo da hospitalização.

A hospitalização é considerada uma situação potencialmente traumática, uma vez que separa a criança de seu ambiente e convívio natural, expondo-a a pessoas desconhecidas, rotinas inflexíveis, equipamentos médicos e tratamentos agressivos (BJÖRK; NORDSTRÖM; HALLSTRÖM, 2006; MITRE; GOMES, 2007). A dor evidencia-se através das agulhas, cortes, medicações, entre outros procedimentos invasivos. Imagens, cheiros e sons estranhos no hospital, os quais fazem parte da rotina da equipe de saúde, também podem ameaçar e confundir as crianças (OLIVEIRA; COSTA; NÓBREGA, 2006), alterando seu estado emocional. De acordo com Gouveia (2003), o estado emocional negativo da criança e do adolescente também pode prolongar sua permanência no hospital, já que um enfrentamento inadequado da situaçáo pode atrasar a recuperação deles.

O medo do desconhecido é bastante comum no ambiente hospitalar, visto que grande parte das crianças e adolescentes não está preparada para a realização de exames, não recebe instruçóes da equipe de saúde sobre seu adoecimento. Isso faz com que eles sintam raiva, desespero, irritabilidade, culpa, ansiedade, entre outros sentimentos negativos (FERRO; AMORIM, 2007). De modo geral, as crianças hospitalizadas se sentem limitadas pela internação, pois têm seu brincar restringido, estão distanciadas de seus familiares, impossibilitadas de 
realizar atividades cotidianas e escolares e de visitar amigos e parentes (PFEIFER et al., 2013).

Devido a esses eventos estressores, Parcianello e Felin (2008) revelaram a importância da humanização hospitalar, da orientação da equipe de saúde e da presença da família e do brincar para minimizar esses efeitos da hospitalização, auxiliando os jovens no enfrentamento da hospitalização de modo positivo. Cada sujeito vivencia e percebe seu adoecimento de modo diferente, de acordo com seus valores e experiências (RIBEIRO; PINTO JUNIOR, 2009), entretanto pode-se afirmar que crianças e adolescentes com câncer, devido às repetidas internaçôes, efeitos colaterais do tratamento, afastamento da escola e dos amigos, experimentaráo menos o mundo à sua volta se náo forem criadas alternativas para que essa interaçáo aconteça de forma prazerosa. Nesse sentido, percebe-se a necessidade da utilização de intervenções terapêuticas não medicamentosas para o enfrentamento da patologia e da hospitalizaçáo (PFEIFER; MITRE, 2008).

O brincar é importante para a melhoria do estado emocional de crianças e adolescentes hospitalizados, auxiliando no enfrentamento de situações difíceis (MOTTA; ENUMO, 2002, 2004), possibilitando que a criança ou adolescente construa e reconstrua práticas e significados, desenvolvendo formas criativas e inovadoras de lidar com o inesperado, adaptar-se a novas situaçôes e ambientes, relacionar-se com os outros e consigo própria (REIS; BICHARA, 2010). Quando brincam, os jovens transformam o ambiente onde estáo inseridos, aproximando-o da realidade cotidiana extra-hospitalar, o que pode ter um efeito benéfico durante a internação, auxiliando-os no seu bem-estar (FERRO; AMORIM, 2007; MITRE; GOMES, 2004). Entretanto, isso é pouco explorado nos ambientes hospitalares, já que o modelo biomédico atual destaca a doença, analisando a criança ou adolescente como um corpo adoecido (MELO, 2003).

De acordo com definição da Organização Mundial da Saúde, a saúde não é apenas ausência de doença, mas também bem-estar subjetivo, e essa conceituação traz consigo a necessidade de se considerar não apenas os processos orgânicos causadores da patologia, mas também os aspectos que constituem a saúde mental do indivíduo (REIS; BICHARA, 2010). Isso evidencia a importância da intervenção Caixa de Histórias para crianças e adolescentes hospitalizados, contribuindo para o processo de enfrentamento da hospitalização e favorecendo a recuperação delas. Contar histórias é entreter, educar, esclarecer, explicar e reanimar (GOUVEIA, 2003). Através das histórias, a criança e o adolescente hospitalizado podem fantasiar, esquecendo-se da dor e do sofrimento. Além disso, as histórias auxiliam na recuperação e na aceitação da condição em que se encontram, além de facilitarem sua adaptaçáo ao ambiente hospitalar, contribuindo para a melhora de seu estado geral (CASTANHA; LACERDA; ZAGONEL, 2005). Todos esses aspectos foram observados durante a realização deste estudo. Notou-se, também, que a intervenção Caixa de Histórias foi importante para a mudança positiva do estado emocional de grande parte das crianças do estudo. Segundo Pfeifer et al. (2013), é essencial que a passagem pelo hospital seja mais tênue, permitindo que a criança esteja na presença de seus familiares, criando alternativas que favoreçam a ludicidade $e$ garantindo-lhes espaços próprios para brincar. Todos esses elementos possibilitam estados emocionais positivos (alegre e muito alegre), contribuindo para a melhora do quadro clínico e para uma menor ruptura do cotidiano infantil.

Dessa forma, através dos dados obtidos, notou-se que houve mudança do comportamento emocional das crianças e adolescentes após a experiência com a Caixa de Histórias, demonstrando ser essa uma importante estratégia de enfrentamento da hospitalização de forma positiva.

\section{Conclusões}

O hospital é ainda um local que causa medo e angústia para muitas crianças e adolescentes adoecidos e para seus familiares, e é por isso que programas de humanização têm sido cada vez mais utilizados com o objetivo de combater os efeitos negativos da hospitalização. Dessa forma, através de intervençóes não medicamentosas, as crianças podem desenvolver estratégias positivas de enfrentamento da hospitalização, melhorando a qualidade da internação e promovendo o seu bem-estar.

O Caixa de Histórias mostrou-se uma importante intervenção no auxílio do enfrentamento do tratamento do câncer infanto-juvenil, possibilitando o resgate do universo lúdico, táo importante para um desenvolvimento adequado, e facilitando, assim, a recuperação de um estado saudável.

Através dos resultados da presente pesquisa foi possível identificar que a intervenção Caixa de Histórias possibilitou a modificação positiva do estado emocional de crianças e adolescentes. Os registros de observações feitas durante o Caixa de Histórias (contação da história pelas duplas de graduandas; exploraçáo dos materiais; contação da história com as próprias palavras dos jovens e realização de atividade pelas crianças e adolescentes) apontam que 
a maioria das crianças e adolescentes demonstrou interesse durante toda a intervenção, interagindo com as duplas de graduandas, manipulando os objetos da caixa, prestando atenção na história, participando da atividade proposta, animando-se e desenvolvendo a curiosidade. Assim, notou-se a importância da utilização da Caixa de Histórias nas mudanças de comportamento, socializaçáo e melhoria da capacidade de enfrentamento da hospitalização das crianças e adolescentes do estudo.

\section{Referências}

ALDISS, S. et al. What is important to young children who have cancer while in hospital? Children \& Society, London, v. 23, n. 2, p. 85-98, 2008. http://dx.doi. org/10.1111/j.1099-0860.2008.00162.x

ASSUMPÇÃO JÚNIOR, F. B. et al. Escala de Avaliaçáo da qualidade de vida (Autoquestionaire qualité de vie enfant imagé): validade e confiabilidade de uma escala para qualidade de vida em crianças de 4 a 12 anos. Arquivos de Neuropsiquiatria, Sáo Paulo, v. 58, n. 1, p. 119-127, 2000. http://dx.doi.org/10.1590/S0004-282X2000000100018 BAHIA, M. C. B. Estudo da expressão criativa da criança e do adolescente com câncer em casas de apoio. Semina: Ciências Humanas e Sociais, Londrina, v. 23, n. 1, p. 129-130, 2002.

BERNARDINO, M. C. R.; ELLIOTT, A. G.; ROLIM NETO, M. L. Biblioterapia com crianças com câncer. Informação \& Informação, Londrina, v. 17, n. 3, p. 198-210, 2012.

BJÖRK, M.; NORDSTRÖM, B.; HALLSTRÖM, I. Needs of young children with cancer during their initial hospitalization: an observational study. Journal of Pediatric Oncology Nursing, Philadelphia, v. 23, n. 4, p. 210-219, 2006. PMid:16766686. http://dx.doi. org/10.1177/1043454206289737

BRAAM, K. I. et al. Design of the Quality of Life in Motion (QLIM) study: a randomized controlled trial to evaluate the effectiveness and cost-effectiveness of a combined physical exercise and psychosocial training program to improve physical fitness in children with cancer. BMC Cancer, London, v. 10, p. 624, 2010. PMid:21070639 PMCid:PMC2996394. http://dx.doi. org/10.1186/1471-2407-10-624

BRAUN, V.; CLARKE, V. Using thematic analysis in psichology. Qualitative Research in Psychology, London, v. 3, n. 2, p. 77-101, 2006. http://dx.doi. org/10.1191/1478088706qp063oa

BRASIL. Ministério da Saúde. Instituto Nacional do Câncer - INCA. Estimativa 2012: incidência de câncer no Brasil. Rio de Janeiro: INCA, 2011. Disponível em: <http:// www.inca.gov.br/estimativa/2012/estimativa20122111. pdf>. Acesso em: 19 jun. 2013.

CASTANHA, M. L.; LACERDA, M. R.; ZAGONEL, I. P. S. Hospital: lugar para o enfermeiro cuidar do imaginário? Acta Paulista de Enfermagem, São Paulo, v. 18, n. 1, p. 94-99, 2005.

FERRO, F. O.; AMORIM, V. C. O. As emoções emergentes na hospitalização infantil. Revista Eletrônica de Psicologia, Maceió, v. 1, n. 1, p. 124-136, 2007.

GARCIA, N. R. ; PFEIFER, L. I.; PANUNCIOPINTO, M. P. As caixas de histórias como estratégia de enfrentamento da hospitalização infantil: a perspectiva de profissionais da saúde. Revista de Terapia Ocupacional da Universidade de São Paulo, v. 23, n. 2, p. 169-177, 2012. GOUVEIA, M. H. Viva e deixe viver: histórias de quem conta histórias. São Paulo: Globo, 2003.

KAATSCH, P. Epidemiology of chidhood cancer. Cancer Treatment Reviews, New York, v. 36, n. 4, p. 277-285, 2010. PMid:20231056. http://dx.doi.org/10.1016/j. ctrv.2010.02.003

LEITE, T. M. C.; SHIMO, A. K. K. Uso do brinquedo no hospital: o que os enfermeiros brasileiros estão estudando? Revista da Escola de Enfermagem da USP, São Paulo, v. 42, n. 2, p. 389-395, 2008. http://dx.doi.org/10.1590/ S0080-62342008000200025

MACIEIRA, R. C.; BARBOZA, E. R. C. Olhar PacienteFamília: incluindo a unidade de cuidados no atendimento integral. In: ASSOCIAÇÃO BRASILEIRA DE LINFOMA E LEUCEMIA - ABRALE. Transdisciplinaridade em Oncologia: caminhos para um atendimento integrado. São Paulo: HR Gráfica e Editora, 2009. p. 119-126.

MELO, L. L. Do vivendo para brincar ao brincando para viver: o desvelar da criança com câncer em tratamento ambulatorial na brinquedoteca. 2003. $178 \mathrm{f}$. Tese (Doutorado)-Universidade de São Paulo, Ribeirão Preto, 2003.

MENEZES, C. N. B. et al. Câncer infantil: organização familiar e doença. Revista Mal-Estar e Subjetividade, Fortaleza, v. 7, n. 1, p. 191-210, 2007.

MITRE, R. M. A.; GOMES, R. A promoção do brincar no contexto da hospitalização infantil como ação de saúde. Ciência \& Saúde Coletiva, Rio de Janeiro, v. 9, n. 1, p. 147-154, 2004.

MITRE, R. M. A.; GOMES, R. A perspectiva dos profissionais de saúde sobre a promoção do brincar em hospitais. Ciência \& Saúde Coletiva, Rio de Janeiro, v. 12, n. 5, p. 1277-1284, 2007.

MORENO, R. L. R. et al. Contar histórias para crianças hospitalizadas: relato de uma estratégia de humanização. Pediatria, Sáo Paulo, v. 25, n. 4, p. 164-169, 2003.

MOTTA, A. B.; ENUMO, S. R. F. Brincar no hospital: câncer infantil e avaliação do enfrentamento da hospitalização. Psicologia, Saúde \& Doenças, Lisboa, v. 3, n. 1, p. 23-41, 2002.

MOTTA, A. B.; ENUMO, S. R. F. Brincar no hospital: estratégia de enfrentamento da hospitalização infantil. Psicologia em Estudo, Maringá, v. 9, n. 1, p. 19-28, 2004. MOTTA, A. B.; ENUMO, S. R. F. Intervenção psicológica lúdica para o enfrentamento da hospitalização em crianças com câncer. Psicologia: Teoria e Pesquisa, Brasília, v. 26, 
n. 3, p. 445-454, 2010. http://dx.doi.org/10.1590/ S0102-37722010000300007

OLIVEIRA, N. F. S.; COSTA, S. F. G.; NÓBREGA, M. M. L. Diálogo vivido entre enfermeira e mães de crianças com câncer. Revista Eletrônica de Enfermagem, Goiânia, v. 8, n. 1, p. 99-107, 2006.

PANÚNCIO-PINTO, M. P.; PFEIFER, L. I.; BRONCA, N. C. A extensão universitária como estratégia de formação na graduação: a experiência do Projeto Caixa de Histórias. Cadernos de Terapia Ocupacional da UFSCar, São Carlos, v. 18, suplemento especial, p. 262 -274, 2010.

PARCIANELLO, A. T.; FELIN, R. B. E agora doutor, onde vou brincar? Considerações sobre a hospitalização infantil. Barbarói, Santa Cruz do Sul, n. 28, p. 147-166, 2008.

PEÇANHA, D. L. N. Câncer: recursos de enfrentamento na trajetória da doença. In: CARVALHO, V. A. et al. (Org.). Temas em Psico-Oncologia. São Paulo: Summus, 2008. p. 209-217.

PEDROSA, A. M. et al. Diversão em movimento: um projeto lúdico para crianças hospitalizadas no Serviço de Oncologia Pediátrica do Instituto Materno Infantil Prof. Fernando Figueira, IMIP. Revista Brasileira de Saúde Materno-Infantil, Recife, v. 7, n. 1, p. 99-106, 2007.

PFEIFER, L. I. et al. Emotional state of children in hospital setting. Topics About Development, São Paulo, v. 19, n. 104, p. 25-41, 2013.

PFEIFER, L. I.; MITRE, R. M. A. Terapia Ocupacional, dor e cuidados paliativos na atenção à infância. In: DE CARLO, M. M. R. P.; QUEIROZ, M. E. G. Dor e cuidados paliativos: Terapia Ocupacional e interdisciplinaridade. São Paulo: Roca, 2008. p. 258-287.

POLIT, D. F.; BECK, C. T. Nursing research: principles and methods. 7. ed. Philadelphia: Lippincott Williams \& Wilkins, 2004.
REIS, K.; BICHARA, I. A brincadeira como ação no mundo: o modus operandi da criança no enfrentamento da doença e da hospitalização. In: PÉREZ-RAMOS, A. M. Q.; OLIVEIRA, V. B. Brincaré saúde: o lúdico como estratégia preventiva. Rio de Janeiro: Wak, 2010. p. 77-99.

RIBEIRO, C. R.; PINTO JUNIOR, A. A. A representação social da criança hospitalizada: um estudo por meio do procedimento de desenho-estória com tema. Revista da SBPH, Belo Horizonte, v. 12, n. 1, p. 31-56, 2009.

ROLLINS, J. A. Tell me about it: drawing as a communication tool for children with cancer. Journal of Pediatric Oncology Nursing, Philadelphia, v. 22, n. 4, p. 203-221, 2005. PMid:15994339. http://dx.doi. org/10.1177/1043454205277103

SANTOS, V. M. D. Análise do processo de capacitação do graduando de terapia ocupacional para atuar junto a crianças hospitalizadas através de caixas de histórias. 2008. 90 f. Monografia (Trabalho de Conclusão em Terapia Ocupacional)-Universidade de São Paulo, Ribeirão Preto, 2008.

SILVA, A. M.; GALlEGO, E. T.; TEIXEIRA, M. C. T. V. Habilidades intelectuais de crianças com câncer e crianças não portadoras da doença. Avaliação Psicológica, Porto Alegre, v. 5, n. 1, p. 33-41, 2006.

SIEGEL, S.; CASTELLAN JUNIOR, N. J. Estatistica não-paramétrica para as ciências do comportamento. Porto Alegre: Bookman, 2006.

SOARES, M. E. B. S.; GUIMARÃES, R. N.; RIBEIRO, C. A. O significado da medicação intratecal para a criança pré-escolar: expresso em sua brincadeira. Revista Paulista de Enfermagem, São Paulo, v. 22, n. 3, p. 268-276, 2003. VASCONCELLOS, E. A.; GIGLIO, J. S. Introdução da arte na psicoterapia: enfoque clínico e hospitalar. Estudos de Psicologia, Campinas, v. 24, n. 3, p. 375-383, 2007.

\section{Contribuição dos Autores}

Nathália Rodrigues Garcia-Schinzari e Luzia Iara Pfeifer participaram da concepção do manuscrito, organização de fontes e/ou análises, redação e revisão do texto. Amanda Mota Pacciulio Sposito participou da organização de fontes e/ou análises, redação e revisão do texto. Jair Lício Ferreira Santos, Lucila Castanheira Nascimento e Maria Paula Panúncio-Pinto participaram da organização de fontes e/ou análises e revisão do texto.

\section{Notas}

${ }^{1}$ Esse artigo contou com auxílio financeiro do CNPq - PIBIC, sendo que todos os procedimentos éticos vigentes foram cumpridos. 